\title{
Identification of Hazardous Road Sections: Crash Data versus Composite Index Method
}

\author{
Intan Suhana M. R., Hussain Hamid, Law Teik Hwa, and Ahmad Farhan
}

\begin{abstract}
In current road safety practices, the identification of hazardous road sections are normally based on crash data. However, the information provided by crash data may not be adequate to explain the causal factors that lead to a crash. Therefore, a different kind of road safety indicator that can extensively describe the actual road environment problems of a road section is considered essential. This paper considered fourteen road environment indicators based on their abilities to portray current road environment conditions and their potential towards road crash incidence. These indicators were collected using naturalistic driving technique within the $80-\mathbf{k m}$ road length connecting Kuantan and Maran town in the state of Pahang, Malaysia in which the composite road environment risk index was finally developed. This composite road environment risk index is found to be a useful proactive method to identify the potential problematic road sections that require urgent road improvement works as compared to the reactive crash data analysis method.
\end{abstract}

Index Terms-Hazardous road sections, crash data, road environment, composite index, proactive method.

\section{INTRODUCTION}

Traffic crash statistics such as crash frequencies, crash severities, number of fatalities and amount of material damages are common types of road safety performance level indicators accepted worldwide [1]. However, the usage of these types of statistics has received much attention from various road safety experts on its ability in defining true factors influencing the crash [2], [5]. Apart from that, it is stated that the reality of traffic safety in its broad sense cannot only be captured by simple statistical indicators of rates of casualties and fatalities [4].

Crashes referred to as the 'worst case scenarios' [4], [5], [2], [6] is actually a result of series of inter-related conditions and can be prevented by conducting early assessment on the physical condition of the road and hazards that largely contribute to crash occurrences. Nevertheless, crash is a reactive measure to determine problematic road areas since crashes have to occur first before the areas can be regarded as problematic for subsequent countermeasure. Besides that, reactive measures may also be linked to other issues such as random variations in crash data and the quality of the entered data. These issues are highly important when dealing with identification of problematic locations

Manuscript received March 11, 2014; revised May 12, 2014

Intan Suhana Mohd Razelan is with Universiti Putra Malaysia and also a lecturer with Universiti Malaysia Pahang, Malaysia (e-mail intan@ump.edu.my).

Hussain Hamid and Law T. H. are with the Department of Civil Engineering, Universiti Putra Malaysia, Malaysia (e-mail: hushamid@upm.edu.my, lawteik@upm.edu.my).

Ahmad Farhan is with the School of Civil Engineering, Universiti Science Malaysia, Malaysia (e-mail: cefrh n@usm.my).
The development of road assessment program (RAP) that was introduced in the European countries through Euro RAP in year 1999 gave a new perspective in evaluating road safety level of road sections. RAP was established with an objective to improve the safety of road by inspecting the risk condition of the selected roads, giving star rating to the roads and finally proposing safer road investment plans to upgrade the status of the risky roads. Meanwhile, in early year 2000, composite index theory has been introduced as another form of instrument in evaluating road safety level. The Road Safety Development Index (RSDI) [3] is one of the examples of composite index used for comparing safety performance among countries. RSDI have been accepted and reviewed by various researchers in road safety fields and the development of RSDI has become a kick off for studies in road safety index for the purpose of comparing among countries [6]-[8]. However, the use of composite index to evaluate safety levels of road sections is yet to be explored.

\section{RESEARCH AIMS}

This research aims to develop a proactive road safety indicator as a supplement to the currently used method i.e. crash data. The outcome from this research can portray the actual situation at problematic road areas as well as act as a basis for further road improvement. The development of this new indicator will allow problematic road areas to be correctly identified over a longer stretch of road network. This is thought to be useful especially for the developing countries that do not have any other indicators to evaluate its road safety performance level apart from the crash data.

\section{DATA COLLECTIONS}

The study areas were segmented into homogenous sections and the road environment data with potential risk to car drivers were collected in every section. A $500-\mathrm{m}$ section is considered as the best length in collecting the road environment data. A section shorter than 500-m may produce a set of highly repetitive data while a longer length may increase the chances of losing much details of the overall data.

The section length is similar throughout the study area regardless of the topography and geometric profiles of the road. The research work adopted naturalistic driving method to capture the road environment attributes that are risky to car drivers in each road section. The participating drivers were required to drive their own vehicle naturally and freely.

\section{A. Research Areas}

The data collection was carried out along Federal Road 2 from KM 2 to KM 82.5 along the Peninsula of Malaysia. This 
trunk road stretch was selected for this study upon consideration on the variability of the road environment. This road passes through major towns such as Kuantan and Maran, residential areas, villages, business centers and educational areas including primary schools, secondary schools and higher institutions, plantation areas and also reserved forest. The surrounding areas of the road exhibited environments that are typical along any other federal roads in Malaysia. Overall, more than $50 \%$ of research area is a dual carriageway road separated by the medians, while the rest are of two-way single carriageway roads.

Federal Road 2 was originally constructed to transport goods between Port Klang in the state of Selangor and Kuantan Port in the state of Pahang. The road is also one of the route options for travelers between Kuantan and Kuala Lumpur. As such, the road is heavily used by long distance motorists travelled at maximum allowable speed and slower heavy vehicles travelling between the two ports. In addition, the road is also heavily used by local commuters. Therefore the risk of crash is rather high considering that long distance motorists had to interact with the short distance commuter traffic and also several road conditions such as access, u-turn and signalized intersection meant for the residents along the roads.

\section{DEVELOPMENT OF COMPOSITE ROAD ENVIRONMENT RISK INDEX}

Normally, variables are selected based on its relevance, accessibility and soundness to the study [9]. On the other hand, indicator is more focused on the issue or the outcome that will be derived from the indicators. Indicator is defined as a series of observed facts that can reveal real statement or assertion of verified information about something that has happened [10].

At the initial stage of this research, fourteen indicators that portray various road environment aspects with high potential risks toward drivers were chosen. Principal component analysis was used to explore whether these indicators were sufficient in explaining the targeted dimensions and whether they are statistically well-balanced in producing a reliable composite index. One of the most important aspects in the composite index is the existence of interrelationship between the indicators. This is essential since the final outcome is derive from the combination of these indicators. Thus, if there are no relationships between these indicators, the outcome would be misleading. Multivariate analysis can minimize the chances of having a weak composite index by assessing the suitability of the indicators beforehand.

$$
I_{q r s}^{t}=x_{q r s}^{t}-x_{q r s=r s}^{t} / \sigma_{q r s=r s}^{t}
$$

where,

$$
\begin{gathered}
I_{q r s}^{t}=\text { normalized indicator for each road section } \\
x_{q r s}^{t}=\text { individual indicator } \\
x_{q r s=r s}^{t}=\text { mean of indicators across road section } \\
\sigma_{q r s=r s}^{t}=\text { standard deviations of indicators across } \\
\text { road section }
\end{gathered}
$$

Normalization is carried out to ensure that all indicators are comparable among each other regardless of their units of measurement. By using the standardization formula in (1), standardized data for all indicators in each road section were prepared.

Weighting is very important in the development of composite index to ensure that the most influential indicators were treated differently from the other indicators and vice versa. Principal component analysis (PCA) is one of the data reduction techniques used to explore data for further analysis. The original set of data will be reduced to form another set of data containing fewer variables known as component. PCA is highly dependent on the correlations between indicators where the newly developed components contain list of original indicators that are highly correlated among each other as well as among the indicators and components.

The final outcome of the PCA is a component coefficients matrix where the coefficient value of each indicator in each component is calculated. The coefficient values indicate the strength of correlation and direction of each indicator in each component. Consequently, highly correlated indicator represents the most significant indicator in that component and with its high value; it will dominate the calculation of composite index when used as indicator weight. By adopting the basic principles of correlations between indicators and components, the coefficients value of each indicator produced in PCA analysis is regarded as the indicator weight. The advantage of using the PCA coefficient as indicator weight is that the highly correlated indicator will give high coefficient value thus reflects the level of influence of the indicator in defining the risk level of road section. Therefore, the main risk contributor of the study areas is directly indicated. Besides that, when the weight of all indicators are utilize to form a composite index, combination of risk generated from different indicators can also be evaluated.

The development of composite index adopts weighted sum-score method as in Eq.2 where the weight of each indicator is multiplied to the scaled score for each indicator before summing up all products for each road section. The scaled score is also called a standardized score in which each indicator is scaled to the same mean and standard deviation. One advantage of the weighted sum score method is that items with the highest loading on the factor would have the largest effect on the factor score [11]. This is exactly what this research needs since indicators with high loading should have more effects on the composite index calculation. Hence, the major risk contributory factor in that particular road section can be directly identified.

where,

$$
\text { Composite Index, } C I_{R S}=\sum S D_{R S} \times W_{i}
$$

$C I_{R S}=$ Composite index for each road section

$S D_{R S}=$ Standardized data for each indicator in each road section

$$
W_{i}=\text { Weight of each indicator }
$$

Validating process between the calculated composite index for each section and total number of crash is carried out to specifically point out which composite index has a significant correlation with real world conditions.

\section{A. Composite Road Environment Risk Index}

As soon as the recording sessions were completed, the transcription process was carried out. The main datasets were prepared in excel format before transferring it to SPSS datasheet for further analyses. Table I shows the descriptive 
analysis of twelve continuous indicators selected as a basis of the development of composite road environment risk index in this study area.

TABLE I: DESCRIPTIVE ANALYSIS FOR ROAD ENVIRONMENT INDICATORS

\begin{tabular}{|c|c|c|c|c|}
\hline & $\mathrm{N}$ & Mean & $\begin{array}{l}\text { Std. } \\
\text { Dev. }\end{array}$ & $\begin{array}{l}\text { Skew } \\
\text { ness }\end{array}$ \\
\hline Num. of Motorcycle & 161 & 1.47 & .699 & .935 \\
\hline Num. of Pedestrian & 161 & 99 & 1.33 & 1.15 \\
\hline $\begin{array}{l}\% \text { of Poor Roadway } \\
\text { Condition }\end{array}$ & 161 & 42.91 & 23.33 & .23 \\
\hline Num. of Lanes & 161 & 1.55 & .732 & 1.22 \\
\hline$\%$ of Unpaved Shoulder & 161 & 38.14 & 37.32 & .36 \\
\hline $\begin{array}{l}\% \text { of Poor Road } \\
\text { Delineation }\end{array}$ & 161 & 37.29 & 29.33 & .32 \\
\hline$\%$ of Roadside Dev & 161 & 29.93 & 30.59 & .76 \\
\hline $\begin{array}{l}\text { Num. of Non-Signalized } \\
\text { Access }\end{array}$ & 161 & 1.97 & 1.90 & 1.14 \\
\hline $\begin{array}{l}\text { Num. of Signalized } \\
\text { Intersection }\end{array}$ & 161 & .07 & .25 & 3.45 \\
\hline$\%$ of Road Without Median & 161 & 57.20 & 47.40 & -.34 \\
\hline Num of Heavy Vehicle & 161 & 1.56 & 1.53 & 1.16 \\
\hline Actual Driving Speed & 161 & 75.17 & 13.25 & -.99 \\
\hline
\end{tabular}

\begin{tabular}{lc|r}
\multicolumn{2}{c}{ TABLE II: KMO AND BARTLETT'S RESULTS } \\
\hline \multicolumn{2}{c}{ Kaiser-Meyer-Olkin Measure of } \\
Sampling Adequacy. & .822 \\
\hline Bartlett's Test of & Approx. Chi-Square & 665.8 \\
Sphericity & & 75 \\
& Df & 45 \\
& Sig. & .000 \\
\hline
\end{tabular}

By restricting the skewness range of between +3 and -3 , the above descriptive analysis results show that the number of signalized intersection has skewness value of 3.454 while other indicators have skewness values within the acceptable range. This indicator seems to have normality problem, thus a Kolmogorov-Smirnov test of normality was carried out to check on its normality. The results from this normality test show that this indicator is not normally distributed (Sig. = $0.0001)$. It means that this indicator have high potential to be discarded from the datasets if the correlation analysis and factorability analysis carried out during multivariate analysis show that this indicator would cause a weak factorability result in the development of the composite index.

According to the correlation result and communalities values of the subsequent analysis, four indicators i.e. poor roadway conditions, percentage of poor road delineations, existence of non-traversable object at roadside and number of accesses were identified to have weak correlations with other indicators indicating these indicators are not suitable to be used in the development of the composite index.

The suitability of the indicators in producing good composite index was checked by employing principal component analysis as the extraction method to all indicators. Adopting exploratory approach, several analyses were performed using different sets of indicators in each trial until a satisfactory combination of indicators was achieved. Each trial seeks a high KMO value as well as high variances explained by the extracted components.

Table II shows the results of Kaiser-Meyer-Olkin (KMO) and Bartlett's test of sphericity regarded as the best combination in producing good composite index for this study area. The KMO and Bartlett's results show that the KMO results of this road environment dataset is 0.822 and the Bartlett's test has a significance value of 0.0001 indicating that the datasets has a good factorability since the cut off point for KMO is 0.6 and a $p$ value less than 0.05 for Bartlett's test.

After checking for indicator's factorability, the amount of variance explained by each indicator was checked. This information is important to investigate which indicator would not fit well with other indicators in the developed components. A communalities value of less than 0.300 indicated that the indicator is not suitable to be part of the composite index. The communalities table is presented in Table III.

\begin{tabular}{c|cc} 
TABLE III: COMMUNALITIES \\
\hline Road Environment Indicators & Initial & $\begin{array}{c}\text { Extr } \\
\text { acti } \\
\text { on }\end{array}$ \\
\hline Number of Motorcycle & 1.000 & .561 \\
Number of Pedestrian & 1.000 & .687 \\
Number of Lanes & 1.000 & .713 \\
Percentage of Unpaved Shoulder & 1.000 & .500 \\
Percentage of Roadside Dev & 1.000 & .514 \\
Number of Signalized Intersection & 1.000 & .363 \\
Percentage of Road Without Median & 1.000 & .826 \\
Lane Changing Opportunity & 1.000 & .401 \\
Number of Heavy Vehicle & 1.000 & .553 \\
Actual Driven Speed & 1.000 & .575 \\
\hline \multicolumn{3}{c}{ Extraction Method: Principal Component Analysis. } \\
\hline
\end{tabular}

\begin{tabular}{l|cc}
\multicolumn{3}{c}{ TABLE IV: ROTATED COMPONENT MATRIX } \\
\hline \multicolumn{1}{c}{ Road Environment Indicators } & \multicolumn{2}{c}{ Component } \\
& 1 & 2 \\
\hline Number of Motorcycle & .414 & .624 \\
Number of Pedestrian & .682 & .471 \\
Number of Lanes & .772 & .341 \\
Percentage of Unpaved Shoulder & -.707 & \\
Percentage of Roadside Dev & .541 & .471 \\
Number of Signalized Intersection & & .584 \\
Percentage of Road Without Median & -.880 & \\
Lane Changing Opportunity & .630 \\
Number of Heavy Vehicle & -.450 \\
Actual Driven Speed & .591 \\
\hline \multicolumn{2}{l}{ Extraction Method: Principal Component Analysis. } \\
Rotation Method: Varimax with Kaiser Normalization. ${ }^{\text {a }}$ \\
\hline
\end{tabular}

The above results show that all indicators have acceptable communalities values meaning that all of these indicators have high potential in producing good composite index. It is important to note that although the number of signalized intersection is not normally distributed, the communalities values of these indicators (communalities $=0.363$ ) show that it managed to pass the cut-off point of 0.300 . Therefore this indicator is included during the process of developing the composite index.

After the list of indicators to be used as a basis for the development of composite index is obtained, the process of developing the composite index is nearly completed. From the ten initial indicators, smaller numbers of components were extracted. Using principal component analysis as the extraction method, the variance explained by each component, the cumulative variances explained by all components, and most importantly the number of components extracted from the initial ten indicators were revealed.

The extraction results revealed the presence of two components with eigenvalues exceeding 1 (Kaiser Criterion) of variances $42.649 \%$ and $14.269 \%$ respectively. The cumulative variance explained by these components is $56.918 \%$. Adopting the parsimony rules of explaining high variance while keeping as few components as possible, a total 
variance exceeding $50 \%$ is good enough for the components to be accepted [12].

Table IV shows that in each component, the value of each indicator explained how much it relates to the component. Component 1 shows that number of lanes, number of pedestrian and lane changing opportunity has the highest positive values while component 2 is dominated by the number of motorcycles, number of heavy vehicles and number of signalized intersection. As the highest loading values in each component were used to interpret and name the components, the road environment risk factor for Federal Road 2 translated by these components are infrastructure environment risk factor represented by component 1 and operational environment risk factor represented by component 2.

The weight for each indicator in each component was obtained from the component score coefficient matrix. The indicators weights were used in the subsequent analysis where calculations of individual index were carried out. Before the calculation of the individual index could be done, the dataset for each indicator were standardized so that every indicator will have comparable sets of data where it could be combined together to produce the composite index. Table V shows part of calculation sheet for the determination of individual index from Section I to Section VII, and for Indicator 1 and 2 .

It is important to note that this calculation sheet was prepared for ten indicators vertically across 161 road sections horizontally using weight of indicators from both components. When the calculation process was completed, two composite indexes were developed; i.e., composite index 1 for infrastructure environment risk factor and composite index 2 for operational environment risk factor. Parts of individual index calculations are shown in Table $\mathrm{V}$.

\begin{tabular}{c|c|ccc}
\multicolumn{4}{c}{ TABLE V: CALCULATION OF INDIVIDUAL INDEX - COMPONENT } \\
\hline $\begin{array}{c}\text { Indi } \\
\text { cato } \\
\mathbf{r}\end{array}$ & & $\mathrm{S} 1$ & $\mathrm{~S} 2$ & $\mathrm{S3}$ \\
\hline \multirow{4}{*}{$\mathbf{1}$} & & & & \\
& Number of Heavy & $\mathbf{1}$ & $\mathbf{1}$ & $\mathbf{1}$ \\
& Veh. & & & \\
& mean & 1.553 & 1.553 & 1.553 \\
& SD & 1.532 & 1.532 & 1.532 \\
& Standardized data,S & -0.361 & -0.361 & -0.361 \\
& Weight,W & .430 & .430 & .430 \\
& Ind. Index (S*W) & -0.155 & -0.155 & -0.155 \\
\hline \multirow{4}{*}{$\mathbf{2}$} & Number of Lanes & $\mathbf{3}$ & $\mathbf{3}$ & $\mathbf{4}$ \\
& mean & 1.550 & 1.550 & 1.550 \\
& SD & 0.732 & 0.732 & 0.732 \\
& Standardized data,S & 1.981 & 1.981 & 3.347 \\
& Weight,W & .031 & .031 & .031 \\
& Ind. Index (S*W) & 0.061 & 0.061 & 0.103 \\
\hline
\end{tabular}

Calculations of composite indexes were completed by adding up all the individual indexes in every section vertically. As a result, each road section will have a composite index value calculated across all indicators thus making this value highly sensitive with the individual index values. Slight changes in the road environment data will cause direct changes in the individual index and also the composite index. This criterion is very important since the accuracy and the applicability of the composite index is highly dependent on its ability to trace changes in the current road conditions. This is because the road sections risk levels are highly dependable on the composite index values assigned for them. Fig. 1 shows the position of each road section according to their composite index values for infrastructure environment risk factor.

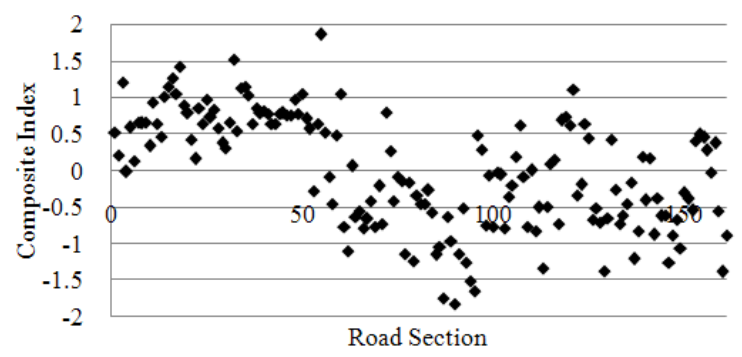

Fig. 1. Road section's positions based on composite index 1: infrastructure environment.

It can be observed that there were huge differences in the position of the road sections for several road sections. The first 30 kilometers of the road is observed to have high composite index values compared to the rest of road. This may be due to the design of the road itself where the first $30 \mathrm{~km}$ of the road is a double carriageway road separated by median while the remaining study area is a two-way single carriageway. Fig. 2 presented the position of the road section based on composite index 2 or based on the road operational environment standpoint.

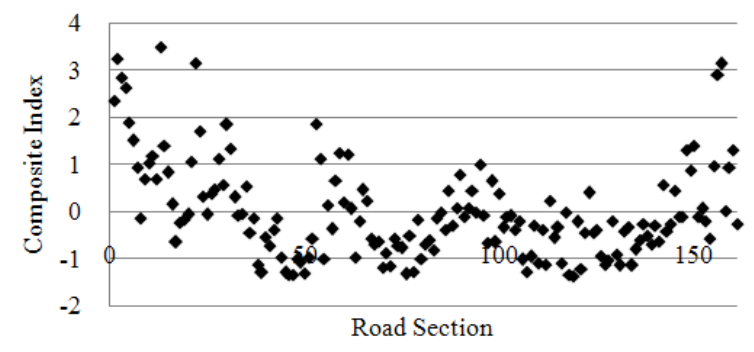

Fig. 2. Road section's positions based composite index 2: operational environment.

Fig. 2 reveals the positions of each road section based on the composite index 2; the road operational environment risk factor. As this composite index is mainly affected by number of motorcycles and number of heavy vehicles, the fluctuating trend as observed in Fig. 2 may be caused by these two indicators where sections with high number of motorcycles and heavy vehicles have higher composite index values compared to other sections.

Validation is the final and highly important step in development of composite index. To ensure that the developed composite index could be used in the real world conditions, the outcome must have significant correlations with the real world data. The total number of crashes for Federal Road 2 is shown in Fig. 3.

A statistical method of Spearman's rank-order correlation coefficient method was chosen as the validation method for this research. An acceptable correlation coefficients value is aimed at not only to validate the developed composite index but also to prove the role of road environment conditions in producing risk as one of the crash contributory factors on the federal roads in Malaysia.

Results from the Spearman Rank-Order-Correlations proved that composite index 2 has significant correlation with the total number of crashes having a correlation coefficient value of 0.574 . The result indicated that the risk from operational environment factors has significant 
contributions toward crash occurrences for this study area. This result provide evidences that the operational environment factors for this area should be urgently tackled and the countermeasures should focused on the aspects of heavy vehicles and motorcycles flows especially at signalized intersections areas.

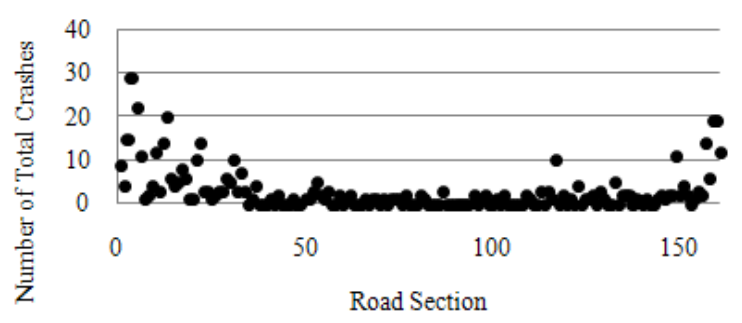

Fig. 3. Total number of crashes per section.

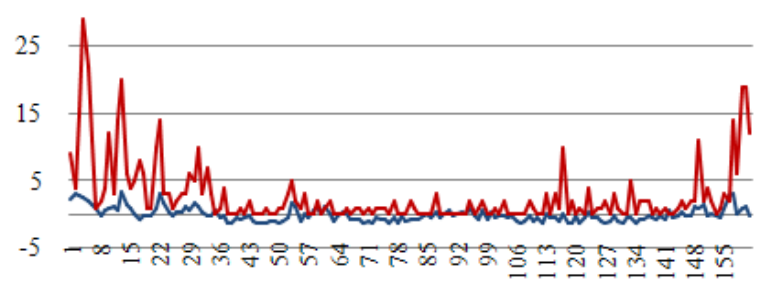

Composite Index 2 Total Crash

Fig. 4. Comparison between composite index and total number of crash: federal road 2.

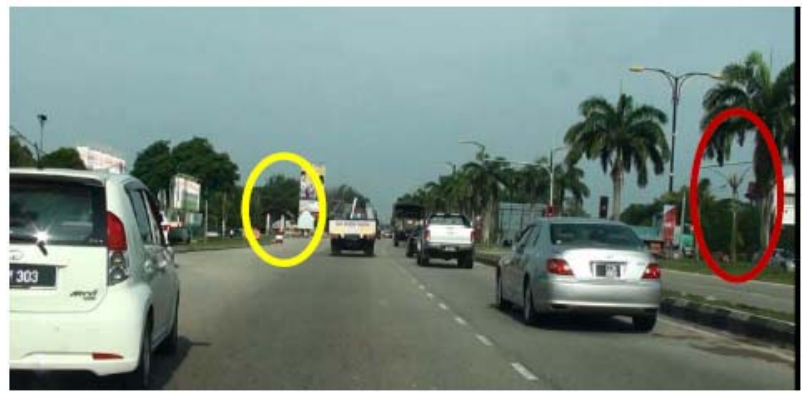

Fig. 5. Road environment at section IV, federal road 2.

\section{COMPOSITE ROAD ENVIRONMENT RISK INDEX VS. CRASH} DATA

The main outcomes generated from both crash data and composite index is the identification of poor road sections. Crash data would identify poor road sections based on at least 3 number of similar type of crashes or at least 5 number of different type of crashes occurring within 3 years (Public Work Department, Malaysia). Meanwhile, composite index identified poor road section in terms of the risks generated from selected road environment aspects representing current road environment conditions. However, the crash data method is a reactive measure while the composite index is a proactive measure in the approach to prevent or reduce road accidents o the road. Since both methods are attempts to identify hazardous road sections, it is worth to compare and discuss the final outcome of their different methods by focusing on the following conditions:

1) Sections where both methods agree that the road section is poor and needs remediation.

2) Sections where the two different methods disagree that the road section is poor.

Fig. 4 shows the total number of crash and the composite index values for 161 sections along the study area of Federal Road 2. It can be seen that the total number of crashes along this study area is very high. The highest number of crashes is recorded at Section IV with 29 crash cases (composite index $=2.6211$ ). While the highest composite index value is recorded at section 13 with a composite value of 3.474 (crash data $=20$ ).

The values of crashes and composite index indicated that both methods agree that these two sections are hazardous and posed high accident risk to road users. Fig. 5 shows an image of one spot within Section IV.

A total number of 29 crashes per 500 meter length or about 3 crash cases in every $50 \mathrm{~m}$ reveal that in accordance to the crash data analysis, this section is regarded as a dangerous and poor road section. On the other hand, by scrutinizing this location of road at this direction of traffic only, it can be observed that there are several road environment aspects that could possibly generate risks toward car drivers. The two accesses on the left hand side of the road and one signalized intersection with u-turn on the right hand side of the road could create a major problem to the through traffic. This is because the through traffic had to deal with vehicles entering and exiting the roadway, stopping when the traffic light turns red and also when vehicles are changing lanes.

In addition, the drivers have to be alert on the pedestrians who crossed the roads to/from the residential areas located on the other side (in red circle) of the road, the shopping complex located on the left hand side of the road, and also buses stopping at the bus-stops located on the left side of the road (in yellow circle). The presence of heavy vehicles and motorcycles travelling along the same roadway as the other vehicles should also be noted.

This judgment is consistent with past findings [13] that the share of accidents close to the place of residence is likely to be higher among pedestrians and bicyclists than among motor vehicles. Since bicycle is not a popular mode of transportation in Malaysia, the motorcycles are taken into account instead. Further, since the area is densely concentrated with business activities and residential areas on both sides of the road, the risk in this area is most probably generated by short distance road users. This is also in-line with the outcomes from past research [13] that most road accident risks in cities are contributed by short distance road users because they usually used motorcycles or bicycles and travels at lower speeds as compared to the long distance motorists. Therefore, from the outcome of composite road environment risk index, this road section is high risk based on the following judgments:

1) Since the development located on both sides of the road is rather dense, the existence of accesses (signalized and non signalized) near to each other can be a source of risks to road users.

2) There is no segregated lane for motorcycles travelling to/from the residential areas and the shopping areas.

3) No pedestrian crossing facilities.

4) No appropriate road signage to guide/warn the road users on the traffic movements within this area.

5) Existence of several non traversable objects can be found on the roadside and the median area.

When all these conditions blend together with high traffic volume especially during peak hours (between 1630 hours 
and 2130 hours), this road section will be highly risky leading to crashes. This is because there is a high number of school children generated from nearby secondary school, people coming back from work, and those going for shopping at the nearby shopping complex (mostly between age groups of 25-35 and 35-45 years old. This findings is in consistent to past findings [14]) which reported that when the complexity of a road is high especially during heavy traffic, the performance of drivers are low regardless of age groups which may contribute to greater chances of crash occurrence.

On the road section where there is disagreement in terms of final outcomes between crash data analysis and composite index, the best example is road Section V. It recorded 22 numbers of total crashes and composite index value of 1.8870 . The difference between Section IV (29 crashes) and Section $\mathrm{V}$ ( 22 crashes) is not very large ( 7 crashes) and Section V is still regarded as hazardous road section. Fig. 6 below shows an image of one spot within Section $\mathrm{V}$ to aid for further discussion.

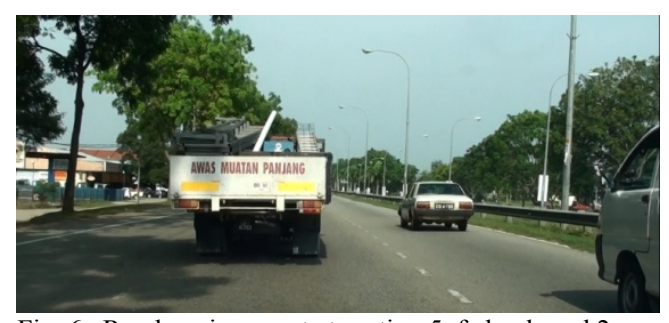

Fig. 6. Road environment at section 5, federal road 2.

From the image in Fig. 6, it is observed that there is one major difference between this Section $\mathrm{V}$ and earlier Section IV (Fig. 5). The business areas are located quite a distance from the main road. A secondary road was built to separate the business areas and the main road. As such, the number of access along the main road is limited thus conflict points are also reduced. However, since the risks could also be generated from other road environment attributes such as guardrails, queue of trees and not forgotten the heavy vehicles that also used this roads, a composite index values of 1.8870 is expected.

Therefore, since the road environment aspects are not the main contributor to crash occurrence in this particular section, this factor was given less priority while planning for an improvement in the aspect of road safety. Given that road improvement aspects is not the main issue in this section, more focus should be placed on human factors such as enforcement on speeding, reckless driving, etc.

\section{CONCLUSIONS}

Overall, the findings from this research showed that development of composite road environment risk index is a useful proactive method in defining poor road sections as compared to the reactive crash data analysis method. It is also an alternative method to identify road sections needing urgent safety improvement works especially when crash data is not available or of poor quality. Moreover, this method is proved to be life saving cost as it doesn't have to wait for crashes to be occurred before any remedial actions are designed.

\section{REFERENCES}

[1] M. Lu, "Modelling the effects of road traffic safety measures," Accident Analysis and Preventions, vol. 38, pp. 507-517, 2006.

[2] B. Wilmots et al., "Analyzing road safety indicator data across Europe: describing, explaining and comparing," in Proc. the 4th Irtad Conference 16-17 September, 2009, Seoul, Korea. pp. 291-299, 2009.

[3] A. H. Ghazwan, "Road Safety Development index. Dissertation," Linkoping University, 2007.

[4] M. N. Hassan, Y. E. Hawas, and M. Maraqa, "A Holistic approach for assessing traffic safety in the united arab emirates," Accident Analysis and Prevention, vol. 45, pp. 554-564, 2012.

[5] Safety Net, Star Rating Roads for Safety-The iRAP Methodology, 2009.

[6] E. Hermans, F. V. D. Bossche, and G. Wets, "Combining road safety information in a performance index," Accident Analysis and Prevention, vol. 40, pp.1337-1344, 2008

[7] Z. Lukasik and A. Szymanek, "Safety and risk in road traffic: selected problems," Transport Problems, vol. 7, no. 2, 2012.

[8] D. Kukic et al., "Selection of a relevant indicator: road casualty risk based on final outcomes," Safety Science, vol. 51, 2013.

[9] OECD, Handbook on Constructing Composite IndicatorsMethodology and User Guide, 2008.

[10] E. Hermans, T. Brijs, and G. Wets, "Developing a theoretical framework for road safety performance indicators and a methodology for Creating a Performance Index," Research Report, 2008.

[11] C. DiStefano et al., "Understanding and using factor scores: considerations for the applied researcher," Practical Assessment, Research and Evaluations, vol. 14, no. 20, 2009.

[12] R. J. Rummel, "Understanding Factor Analysis," Journal of Conflict Resolution, pp. 444-480, 1967.

[13] J. Scheiner and C. H. Rau, "A residential location approach to traffic safety: two case studies from germany, Accident Analysis and Prevention, vol. 43, no. 1, pp. 307-22, 2011.

[14] A. Stinchcombe, G. Sylvain, J. Zhang, P. Montembeault, and M. Bedard, "Fluctuating attentional demand in a simulated driving assessment: the roles of age and driving complexity," Traffic Injury Prevention, vol. 12, no. 6, pp. 576-587, 1997.

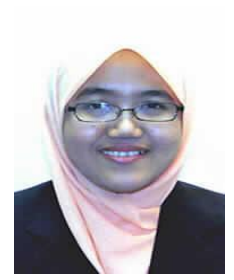

Intan Suhana Mohd Razelan was born in Pahang, Malaysia on 3 October in 1978. She holds a master in transportation engineering and is currently pursuing her $\mathrm{PhD}$ focusing on the area of road safety engineering at Universiti Putra Malaysia. Mrs. Intan Suhana is also a lecturer at Universiti Malaysia Pahang where she develops her research interest in the area of road safety research.

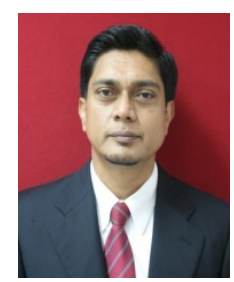

Hussain Hamid was born in Penang, Malaysia on 12 Oct in 1961. He holds a BSc civil eng, MSc (Eng) transport planning and engineering and also a $\mathrm{PhD}$ in highway and transportation engineering. Hussain is currently a senior lecturer at Department of Civil Engineering, Faculty of Engineering, UPM. His research interest is majorly on traffic \& road safety engineering

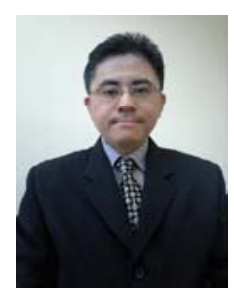

Law Teik Hwa was born in Taiping, Perak in 1971. He holds his master in road safety engineering from Universiti Putra Malaysia and he holds his $\mathrm{PhD}$ in road safety engineering from Imperial College, U.K.

$\mathrm{He}$ is currently a senior lecturer at the Department of Civil Engineering, Universiti Putra Malaysia. His research interest is mainly focued on the area of road safety, intelligent transport system and public transport analysis.

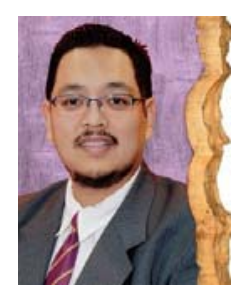

Ahmad Farhan received his $\mathrm{PhD}$ in transport studies from the University of London, United Kingdom. He has a master of science in transport from the Same University. Ahmad Farhan is presently a professor in transport studies and also a dean at the School of Civil Engineering, Universiti Sains Malaysia. He has developed interest in various areas within transportation engineering such as on intelligent transport system, public transport, sustainable transport, road safety, travel behavior and traffic engineering. 